\title{
Oviposition behavior in wild Anastrepha obliqua (Macquart, 1835) (Diptera: Tephritidae): initial study of associative learning related to a protein source
}

\author{
Thamara A. B. S. Leal and Fernando S. Zucoloto \\ Universidade de São Paulo, Ribeirão Preto, Brazil
}

\begin{abstract}
In associative learning, experience enables an animal to associate a conditioned stimulus with some other meaningful stimulus producing either positive or negative effects. In this way, on a subsequent encounter, the response that was previously elicited only by the meaningful stimulus is then elicited by the conditioned stimulus as well. The aim of the present study was to investigate whether wild Anastrepha obliqua (Macquart, 1835) females are able to associate the presence of quinine sulphate (QS) in the composition of oviposition substrates with the presence of brewer's yeast (a protein source). First, the females were submitted to an experience period with artificial substrate containing brewer's yeast + QS (YQS substrate). After this period, the females were allowed to choose between substrates with or without QS. In one group, the substrates contained brewer's yeast (YQS x Y substrates); in the other group, the substrates contained only agar (AQS x A substrates). In the YQS x Y choice situation, a smaller quantity of eggs was found on YQS substrates, only on the first choice day. In the AQS x A choice situation, there was no preference for one of the substrates on each of the three choice days. However, we think it is too early to state that $A$. obliqua females are not able to perform the association in question. These flies show a high behavioral flexibility concerning their oviposition behavior strategies. Besides, this behavior, in this species, includes several stages. Based on it, possible explanations for the results are discussed in this study.Keywords: Brewer's yeast, effect of experience, egg-laying behavior, fruit flies.
\end{abstract}

Received 29 September 2008; received in revised form 11 December 2008 ; accepted 12 December 2008. Available online 29 December 2008.

\section{Introduction}

Previous experience plays an important role in the recognition and preference for the host plant (Dethier, 1982). The effect of experience may derive from a large range of mechanisms, which include habituation, increase in the ability of processing toxicant substances, sensitization, induction and associative learning (Bernays, 1995; Bernays \& Weiss, 1996). According to Bernays (1995), an advantage of the effect of experience to insects, in a whole, is the simplification of the pathways that lead information to the Central Nervous System, contributing to a more efficient search for food and/or an oviposition host, and also to a smaller exposition to dangerous situations (e.g., predation).

ThamaraA. B. S. Leal and Fernando S.Zucoloto, Departamento de Biologia, Faculdade de Filosofia, Ciências e Letras de Ribeirão Preto - Universidade de São Paulo, Brazil. Correspondence regarding this article should be directed to: Fernando S. Zucoloto Faculdade de Filosofia, Ciências e Letras de Ribeirão Preto Universidade de São Paulo Avenida Bandeirantes, 3900 - Ribeirão Preto - SP - Brazil - CEP14040-901. Phone: (+55 16) 3602-3707 E-mail: zucoloto@ffclrp.usp.br
In associative learning, experience enables an animal to associate a stimulus with no specific meaning (conditioned stimulus) with a given meaningful stimulus (unconditioned stimulus) producing either positive or negative effects. In this way, on a subsequent encounter, the response that was previously elicited only by the meaningful stimulus is then elicited by the conditioned stimulus as well (Bernays, 1995). In insects, learning may change the preference for oviposition sites by females that are exposed to different host plants (Cunningham \& West, 2001). Gravid females of Pieris rapae (Linnaeus, 1758) (Lepidoptera), for instance, associate a favorable chemical stimulus of oviposition with the appearance of the acceptable site, which facilitates host selection from a distance (Traynier, 1984).

Anastrepha obliqua (Macquart, 1835) fruit flies are polyphagous, multivoltine and present an oviposition behavior that includes several stages (Aluja, Piñero, Jácome, Díaz-Fleischer, \& Sivinski, 2000) which can be affected by a series of environmental and physiological factors (Dukas, Prokopy, Papaj, \& Duan, 2001).

Feeding on a protein source is important for fruit flies during the larval phase and, specially, in adulthood (Braga \& Zucoloto, 1981; Zucoloto, 2000). However, 
protein sources are not always abundant in natural fruit fly food. Thus, the existence of mechanisms to detect protein-enriched food seems to be advantageous. The same may not happen with carbohydrate that represents an abundant nutrient in natural fruit fly diet (Bateman, 1972). In this context, the occurrence of associative learning related to a protein source in the oviposition behavior would be a strategy that would allow a better offspring performance; besides it makes the search for oviposition sites containing protein much more efficient as well.

The aim of the present study was to investigate whether wild A. obliqua females are able to associate the presence of a compound not related to their habitual oviposition hosts (quinine sulphate - QS) with the presence of protein source in the oviposition substrate. This compound was used in previous studies of associative learning with the same species (Cresoni-Pereira \& Zucoloto, 2006). Since the use of allelochemicals as a sign of nutrient-specific presence in hosts is common among insects, our hypothesis is that females would associate QS with the presence of a protein source.

\section{Methods}

\section{Animals}

Wild adult $A$. obliqua flies were obtained from infested "cajá-manga" - Spondias venulosa (Engler, 1876). The fruits were collected at an experimental farm (Fazenda Experimental do Instituto Agronômico de Campinas) located in Ribeirão Preto, SP, Brazil. They were maintained in a plastic tray $(60 \mathrm{x} 40 \mathrm{x}$ $10 \mathrm{~cm}$ ) with sand until the insects reached the pupae stage. Then, the pupae were placed in acrylic boxes $(11 \times 11 \times 3,5 \mathrm{~cm})$ containing sterilized sand. After the emergence, the adults were placed in groups of $16\left(109,60^{\Uparrow}\right)$ individuals/box (11 x 11 x 7cm) (1 box $=1$ replicate). Two groups were formed with 10 replicates each.

\section{Apparatus}

The acrylic boxes contained three lateral orifices ( $1 \mathrm{~cm}$ in diameter) through which the solid diets and water were offered. Water was offered in small glass test tubes sealed with cotton wool, and the solid diets in pieces were speared in a pin stuck on a cork. Both the water and the solid diet were replaced daily. The solid diet consisted of distilled water $100 \mathrm{ml}$; agar $3.0 \mathrm{~g}$ (Vetec, Rio de Janeiro, Brazil); brewer's yeast $6.5 \mathrm{~g}$ (Oficina de Ervas, Ribeirão Preto, Brazil); sucrose 11.0g (Synth, Diadema, Brazil) and Nipagin $1.5 \mathrm{ml}$ (Merck, Darmstadt, Germany) in $20 \%$ alcoholic solution.

The artificial hosts for oviposition had an oval shape and $6 \mathrm{ml}$ volume. They were wrapped with Parafilm (American Can Company, Detroit, USA) in order to provide a resistance to the female ovipositor, as occurs with the host fruit's skin. The artificial substrates were composed by: YQS substrate $=$ distilled water $100 \mathrm{ml}$; agar 2.5g; brewer's yeast $6.5 \mathrm{~g}$; quinine sulphate $25 \mathrm{mg}$; Y substrate $=$ distilled water $100 \mathrm{ml}$; agar $2.5 \mathrm{~g}$; brewer's yeast $6.5 \mathrm{~g}$; AQS substrate $=$ distilled water $100 \mathrm{ml}$; agar $2.5 \mathrm{~g}$; quinine sulphate $25 \mathrm{mg}$; A substrate $=$ distilled water $100 \mathrm{ml}$; agar $2.5 \mathrm{~g}$.

The compound quinine sulphate was chosen because it is unrelated to $A$. obliqua natural hosts. The quantity of quinine sulphate (Dyne, Rio de Janeiro, Brazil) (25mg/100ml water) was similar to the one used in the composition of the artificial diet used in previous studies (Crisci \& Zucoloto, 2001; Cresoni-Pereira \& Zucoloto, 2006).

\section{Procedure}

As in previous reports (Fontellas-Brandalha \& Zucoloto, 2004), the artificial hosts for oviposition were inserted in experimental boxes from day 18 after the adult emergence, approximately when egg-laying behavior

Table 1. Number of eggs laid on each of the 3-day selection period on YQS (yeast + quinine sulphate) and Y (yeast) substrates by A. obliqua flies which had a previous contact with YQS substrates (Group 1) The results represent the mean \pm standard deviation of 10 experimental boxes. * Indicates significant difference, according to the Wilcoxon test $(p<.05)$.

\begin{tabular}{cccc}
\hline \multirow{2}{*}{ Day of selection } & \multicolumn{2}{l}{ Number of eggs/substrate } & P value \\
\cline { 2 - 4 } & YQS & Y & \\
\hline $1^{\text {st }}$ day & $2.6 \pm 3.24$ & $7.5 \pm 8.10$ & $\mathrm{p}=.020^{*}$ \\
$2^{\text {nd }}$ day & $3.7 \pm 5.14$ & $6.3 \pm 7.50$ & $\mathrm{p}=.129$ \\
$3^{\text {rd }}$ day & $4.8 \pm 5.22$ & $7.2 \pm 6.05$ & $\mathrm{p}=.164$ \\
\hline
\end{tabular}


Table 2. Number of eggs laid on each of the 3-day selection period on AQS (agar + quinine sulphate) and A (agar) substrates by A. obliqua flies which had a previous contact with YQS substrates (Group 2). The results represent the mean \pm standard deviation of 10 experimental boxes. There was no significant difference between pairs, according to the Wilcoxon test $(\mathrm{p}>.05)$.

\begin{tabular}{|c|c|c|c|}
\hline \multirow{2}{*}{ Day of selection } & \multicolumn{2}{|c|}{ Number of eggs/substrate } & \multirow{2}{*}{ P value } \\
\hline & AQS & $\mathbf{A}$ & \\
\hline $1^{\text {st }}$ day & $0.1 \pm 0.32$ & $1.0 \pm 2.00$ & $\mathrm{p}=.250$ \\
\hline $2^{\text {nd }}$ day & $1.8 \pm 2.62$ & $3.5 \pm 6.38$ & $p=.313$ \\
\hline $3^{\text {rd }}$ day & $1.3 \pm 2.41$ & $3.6 \pm 5.17$ & $p=.125$ \\
\hline
\end{tabular}

begins. The artificial substrates were replaced by new ones on a daily basis.

The flies of the two groups were placed with YQS substrates from the $18^{\text {th }}$ day of adult life. Five days were counted taking into account the first day when the presence of eggs on the substrate of each experimental box was detected plus the four following days. On the three days after this period, the flies of Group 1 had to choose between nutritive substrates for them: YQS x Y substrates. The flies of Group 2 had to choose between non-nutritive substrates: AQS x A substrates.

In both groups, we considered 10 experimental boxes with females whose oviposition behavior began until the $35^{\text {th }}$ day after emergence, as a way to standardize the female age. The five-day period of experience was based on previous studies about associative learning related to the A. obliqua feeding behavior (Cresoni-Pereira \& Zucoloto, 2006).

In this work, the oviposition preference was evaluated by the number of eggs that were laid daily on each artificial oviposition substrate.

The experiments were performed under controlled temperature $\left(27 \pm 1^{\circ} \mathrm{C}\right)$ and humidity $(70 \pm 5 \%)$ and a $12: 12$ light/dark cycle, through fluorescent lights (400 lux).

\section{Statistics}

The Wilcoxon test was used to verify the preference for oviposition substrates within the same group. The Mann-Whitney test was used to compare the quantity of eggs that were laid by the females of the two groups. These tests were conducted using the SigmaStat program for Windows Version 2.03 - Jandel Corporation. The level of significance was set at $5 \%$.

\section{Results}

There was a statistically significant difference between the number of eggs that were laid on YQS e Y substrates by the females of Group 1 on the first day of selection. This number was greater on the Y substrate. This difference was not noted on the second and third days of selection (Table 1). In relation to Group 2, the number of eggs that were laid by females was not significantly different between AQS and A substrates on any of the three selection days (Table 2).

A statistically significant difference (Mann-Whitney test, $\mathrm{p}=.026$ ) between the total number of eggs that were laid on the nutritive substrate for A. obliqua (YQS or Y substrates) (Group 1) and on the non-nutritive one (AQS or A substrates) (Group 2) was found (Figure 1).

\section{Discussion}

Secondary compounds that are present in hosts, as quinine, may act as stimulatory or deterrent compounds, according to their concentration (Bernays \& Chapman, 2000; Chapman, 2003). The fact that a secondary compound (allelochemical) is deterrent to an insect does not imply that the insect does not use plants which contain that compound as hosts (Chapman, 2003). Allelochemicals often suppress the activity of cells that respond to stimulants. The suppression is complete when the concentration of compounds is high (Bernays \& Chapman, 2000). We may suppose that quinine sulphate has acted by stimulating cells that respond to deterrents and/or inhibiting cells that respond to stimulatory compounds for oviposition - as may have been the case of brewer's yeast (Fontellas-Brandalha \& Zucoloto, 2004). It would explain the smaller quantity of eggs laid on YQS substrates on the first day of selection, in choice situation YQS x Y (Group 1).

The statistically significant difference between the number of eggs that were laid on YQS and Y substrates on the first day of selection and the "no difference" detected on the second and third days may be explained by the phenomenon of habituation to a deterrent (in this case, to quinine sulphate) in association with the stimulating effect of novelty (provided by substrate containing only brewer's 


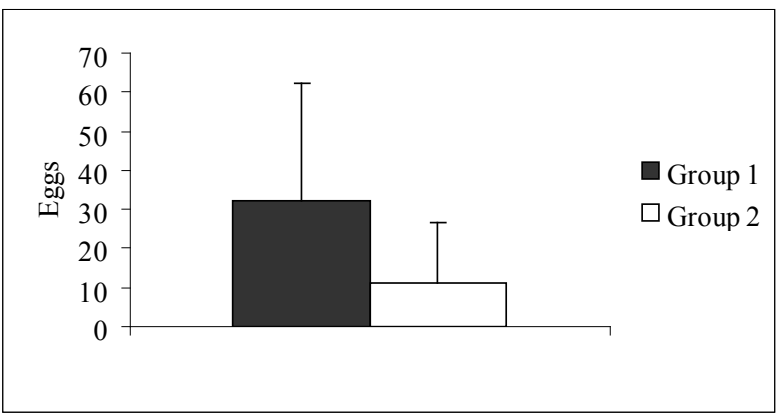

Figure 1. Total number of eggs laid on nutritive substrates for A. obliqua (YQS or Y substrates; Group 1) and non-nutritive substrates (AQS or A substrates; Group 2) during the 3-day selection period. There was significant difference between values, according to the Mann-Whitney test $(p=.026)$. The results represent the mean \pm standard deviation of 10 experimental boxes. $\mathrm{T}^{=}$standard deviation.

yeast). According to Bernays (1995), during habituation there is a waning of response to a stimulus with the repeated exposure to that stimulus. And the stimulating effect of novelty occurs when, during a moment that an insect has a new available host, this insect refuses a certain host that it has already experienced (Bernays, 1995). In this way, the negative response to quinine sulphate may have been reduced during the contact time with this compound (five experience days plus selection days). It may have resulted in a gradual numerical increase in the quantity of eggs laid on YQS substrates. The stimulating effect of novelty, in this context, would also explain the significant difference that was found on the first day of selection, once this was the first day that females had contact with the Y substrate.

The results found in this present study differ from the ones found in the study by Cresoni-Pereira and Zucoloto (2006), where associative learning related to A. obliqua feeding behavior was studied. When the diets for choice had an adequate nutritional value, the flies did not show any preference for the diet with yeast + quinine sulphate or the diet containing only yeast. In the case of the diets without nutritional value, the flies preferred the diet containing agar + quinine sulphate, indicating the occurrence of an association between this compound and the protein source (Cresoni-Pereira \& Zucoloto, 2006). The difference between the study performed by CresoniPereira and Zucoloto (2006) and the present one gives indications of inherent differences between the feeding and oviposition behaviors in A. obliqua.

During feeding, generalist insects, such as $A$. obliqua, obtain a suitable balance of nutrients as a result of a mixture of foods, which allows the dilution of potentially poisonous chemicals that are present in some foods (Bernays \& Minkenberg, 1997). CresoniPereira and Zucoloto (2006) supposed that, as the flies have fed on two blocks of diets (brewer's yeast + quinine sulphate and brewer's yeast), the dilution of quinine sulphate may have enabled the minimization of any effect resulting from the presence of this compound in the insect body. This strategy is not possible during oviposition behavior, so the effect of quinine sulphate was present as previously discussed.

If there were any preference for the AQS substrate in the AQS x A choice situation, we could suggest the hypotheses that $A$. obliqua females associate the presence of quinine sulphate with the presence of protein on oviposition substrates. Even so, we think it is too early to state - based on the experiments performed in the present study - that A. obliqua females are not able to establish the association in question, since the oviposition behavior in A. obliqua includes several stages.

Studies involving associative learning use several parameters to evaluate the existence or inexistence of the capacity of association, as for instance, the number of individuals near a resource, the proboscis extension, the animal position after a given time, the dietary ingestion on one day, and the amount and size of egg batches laid (Dukas, 1998; Faber, Joerges, \& Menzel, 1999; Scherer, Stocker, \& Gerber, 2003; Cresoni-Pereira \& Zucoloto, 2006; Glas, Van Den Berg, \& Potting, 2007). All these parameters involve a combination of behavioral and physiological manifestations that are responses to the sensorial stimuli received. The parameter adopted in the present study - number of eggs laid - is a result of a set of stages which constitute the oviposition behavior of fruit flies: arrival at the fruit, analysis of its physical and chemical characteristics, puncture (aculeus insertion), and egg deposition (Aluja, 1994). In other words, the female fly goes through several stages until it "decides" to lay eggs on a given host.

In this case, we suggest two possibilities (not exclusive because learning is individual). The first one is that the female may have associated the presence of quinine sulphate with the presence of protein on the AQS substrate and it went to this ovipositon site firstly, instead of the A substrate. Next, after evaluating better the AQS substrate characteristics, the female perceived the lack of protein sources, "decided" to lay no eggs on it, and looked for other potential hosts. It may indicate that the lack of nutritional value of the artificial substrate was a determinant factor in the oviposition behavior.

As in experimental boxes from Group 2, during choice period, only non-nutritive substrates were available, some females laid eggs on available substrates; other females probably stored their eggs, which has been suggested by some researchers (Carey, Krainaker, \& Vargas, 1986; Aluja, Díaz-Fleischer, Papaj, Lagunes, \& Sivinsky, 2001). An indication of that egg storage, which occurred as a result of nutritional deficit of AQS and A substrates, is the lower number of eggs laid by females from Group 2 in relation to Group 1.

The second possibility is that the female did not make the association in question, which may have been due to some reasons. Crisci and Zucoloto (2001) hypothesized that 
an artificial diet containing $37.5 \mathrm{mg} \mathrm{QS} / 100 \mathrm{ml}$ diet could suppress food ingestion by Ceratitis capitata (Wiedemann, 1824) larvae. Regarding the feeding behavior of A. obliqua adults, agar diets containing $25 \mathrm{mg} \mathrm{QS} / 100 \mathrm{ml}$ water were considered repellent to the flies (Cresoni-Pereira \& Zucoloto, 2006). In this context, one explanation would be that the quinine sulphate is deterrent for the oviposition behavior of $A$. obliqua, as it was for the feeding behavior; so the negative stimulus resulting from this compound would have prevented the association.

According to Dukas (1998), if a larva presented an innate attraction for yeast or decomposition odor (which indicates yeast or bacterium occurrence), learning to associate the stimulus with these environmental events would not be necessary. In this way, the second explanation for the lack of association of quinine sulphate with the presence of protein would be to suppose that the chemoreceptors involved in the $A$. obliqua oviposition behavior were easily stimulated by the presence of protein (maybe in a low concentration) in a host, making the association with other stimuli unnecessary. It would be possible, since the fruits, which are natural oviposition sites for fruit flies, contain low protein concentration.

A wide range of behaviors performed by a species gives it a higher probability of adapting to a new condition. In the case of polyphagous insects, this behavioral flexibility allows them to keep a large number of hosts (Sugayama \& Malavasi, 2000). As the present study, several reports have cited the plasticity of fruit flies concerning their oviposition behavior strategies. In this sense, further investigations about this behavior deserve to be addressed in future studies.

\section{Acknowledgment}

The authors are grateful to Ana Paula dos Santos and Laércio Massocato for laboratory assistance, and to FAPESP for financial support (Proc. No. 02/11613-9).

\section{References}

Aluja, M. (1994). Bionomics and management of Anastrepha. Annual Review of Entomology, 39, 155-178.

Aluja, M., Díaz-Fleischer, F., Papaj, D.R., Lagunes, G., \& Sivinsky, J. (2001). Effects of age, diet, female density, and the host resource on egg load in Anastrepha ludens and Anastrepha obliqua (Diptera: Tephritidae). Journal of Insect Physiology, 47, 975-988.

Aluja, M., Piñero, J., Jácome, I., Díaz-Fleischer, F., \& Sivinski, J. (2000). Behavior of flies in the genus Anastrepha (Trypetinae: Toxotrypanini). In: M. Aluja \& A.L. Norrbom (Eds.), Fruit flies
(Tephritidae): Phylogeny and Evolution of Behavior (pp. 375410). New York: CRC Press.

Bateman, M.A. (1972). The ecology of fruit flies. Annual Review of Entomology, 17, 493-518.

Bernays, E.A. (1995). Effect of experience on feeding. In: R.F. Chapman \& G. Boer (Eds.), Regulatory Mechanisms in Insect Feeding (pp. 279-306). New York: Chapman \& Hale.

Bernays, E.A., \& Chapman, R.F (2000). Plant secondary compounds and grasshoppers: beyond plant defenses. Journal of Chemical Ecology, 26, 1773-1793.

Bernays, E.A., \& Minkenberg, P.J.M. (1997). Insect herbivores: different reasons for being a generalist. Ecology, 78, 1157-1169.

Bernays, E.A., \& Weiss, M.R. (1996). Induced food preferences in caterpillars: the need to identify mechanisms. Entomologia Experimentalis et Applicata, 78, 1-8.

Braga, M.A.S., \& Zucoloto, F.S. (1981). Estudos sobre a melhor concentração de aminoácidos para moscas adultas de Anastrepha obliqua (Díptera, Tephritidae). Revista Brasileira de Zoologia, 41, 75-79.

Carey, J.R., Krainaker, D.A., \& Vargas, R.I. (1986). Life history of females Mediterranean fruit flies, Ceratitis capitata, to periods of host deprivation. Entomologia Experimentalis et Applicata, $42,159-167$.

Chapman, R.F. (2003). Contact chemoreception in feeding by phytophagous insects. Annual Review of Entomology, 48, 455-484.

Cresoni-Pereira, C., \&. Zucoloto, F.S. (2006). Associative learning in wild Anastrepha obliqua females (Diptera, Tephritidae) related to a protein source. Iheringia, Série Zoologia, 96, 53-56.

Crisci, V.L., \& Zucoloto F.S. (2001). Performance and selection of diets containing the allelochemical compound quinine sulfate by Ceratitis capitata (Diptera, Tephritidae). Revista Brasileira de Entomologia, 45, 275-282.

Cunningham, J.P., \& West, S.A. (2001). Host selection in phytophagous insects: a new explanation for learning in adults. Oikos, 95, 537-543.

Dethier, V.G. (1982). Mechanism of host-plant recognition. Entomologia Experimentalis et Applicata, 31, 49-56.

Dukas, R. (1998). Ecological relevance of associative learning in fruit fly larvae. Behavioral Ecology and Sociobiology, 19, 195-200.

Dukas, R., Prokopy, R.J., Papaj, D.R., \& Duan, J.J. (2001). Egg laying behavior of Mediterranean fruit flies (Diptera: Tephritidae): is social facilitation important? Florida Entomologist, 84, 665-671.

Faber, T., Joerges, J., \& Menzel, R. (1999). Associative learning modifies neural representations of odors in the insect brain. Nature Neuroscience, 2, 74-78.

Fontellas-Brandalha, T.M.L., \& Zucoloto, F.S. (2004). Selection of oviposition sites by wild Anastrepha obliqua (Macquart) (Diptera: Tephritidae) based on the nutritional composition. Neotropical Entomology, 33, 557-562.

Glas, J.J., Van Den Berg, J., \& Potting, R.P.J. (2007). Effect of learning on the oviposition preference of field-collected and laboratoryreared Chilo partellus (Lepidoptera: Crambidae) populations. Bulletin of Entomological Research, 97, 415-420.

Scherer, S., Stocker, R.F., \& Gerber, B. (2003). Olfactory learning in individually assayed Drosophila larvae. Learning \& Memory, $10,217-225$.

Sugayama, R.L., \& Malavasi, A. (2000). Ecologia Comportamental. In: A. Malavasi \& R.A. Zucchi (Eds.), Moscas-das-frutas de Importância Econômica no Brasil - Conhecimento Básico e Aplicado (pp. 103-108). Ribeirão Preto: Holos.

Traynier, R.M.M. (1984). Associative learning in the ovipositional behaviour of the cabbage butterfly, Pieris rapae. Physiological Entomology, 9, 465-472.

Zucoloto, F.S. (2000). Alimentação e Nutrição. In: A. Malavasi \& R.A. Zucchi (Eds.), Moscas-das-frutas de Importância Econômica no Brasil - Conhecimento Básico e Aplicado (pp. 67-80). Ribeirão Preto: Holos. 